\title{
A Fire-Retardant Composite Made from Domestic Waste and PVA
}

\author{
Neni Surtiyeni, Raidha Rahmadani, Neny Kurniasih, \\ Khairurrijal, and Mikrajuddin Abdullah
}

Department of Physics, Bandung Institute of Technology, Jalan Ganeca 10, Bandung 40132, Indonesia

Correspondence should be addressed to Mikrajuddin Abdullah; mikrajuddin@gmail.com

Received 10 April 2016; Accepted 31 May 2016

Academic Editor: Ying Li

Copyright (C) 2016 Neni Surtiyeni et al. This is an open access article distributed under the Creative Commons Attribution License, which permits unrestricted use, distribution, and reproduction in any medium, provided the original work is properly cited.

\begin{abstract}
We report the synthesis of a composite from domestic waste with the strength of wood building materials. We used original domestic waste with only a simple pretreatment to reduce the processing cost. The wastes were composed of organic components (generally originating from foods), paper, plastics, and clothes; the average fraction of each type of waste mirrored the corresponding fractions of wastes in the city of Bandung, Indonesia. An initial survey of ten landfills scattered through Bandung was conducted to determine the average fraction of each component in the waste. The composite was made using a hot press. A large number of synthesis parameters were tested to determine the optimum ones. The measured mechanical strength of the produced composite approached the mechanical properties of wood building materials. A fire-retardant powder was added to retard fire so that the composite could be useful for the construction of residential homes of lower-income people who often have problems with fire. Fire tests showed that the composites were more resistant to fire than widely used wood building materials.
\end{abstract}

\section{Introduction}

Bandung is the fourth largest city in Indonesia, with a population of approximately 2,394,873 (a population density of 14,236 inhabitants $/ \mathrm{km}^{2}$ ) [1]. One major problem faced by large cities in Indonesia is the management of domestic wastes. The problem has been triggered by two primary factors, the lack of adequate waste management facilities and the lack of public awareness for managing domestic wastes. People still have not acquired the awareness to sort their wastes based on type. All of the types of wastes are mixed in one container and then dumped into landfills. Therefore, toxic materials may mix with domestic wastes.

Workers dispose of waste from houses in temporary waste disposal sites using a cart or small transportation vehicle. From this temporary site, wastes are then dumped in a final disposal site by a waste truck. In the final disposal site, wastes are stacked and left to rot or decompose naturally. However, the plastic component in the waste is very difficult to naturally decompose and can threaten the environment. Recycling plastic is more difficult than other materials [2]. Plastic production in large volumes currently requires serious solutions to protect the environment from pollution effects. This step is necessary either during use or after use [3].

Sufficient time is needed for the residential awareness in managing waste to reach the same level as in cities in developed countries. Therefore, it is important to find a shortterm solution in the waste management process while waiting for a realization of the integrated waste management process achieved in developed countries.

More specific to the city of Bandung, wastes dumped in landfills contain multiple types of wastes mixed together. It is very difficult to sort these wastes according to their type due to the time required as well as cost. Components in the waste can be recycled, such as plastic, cans, and bottles, and scavengers usually take these components and sell them to recycling factories. However, the remaining wastes consist of multiple types of materials, including toxic materials, such as batteries and lamps, which contain mercury.

Research on materials for buildings generally is focused on improving the performance of concrete [4-6]. There are relatively little considerations paid to the utilization of domestic wastes to building materials. Some domestic wastes have been recommended for the manufacture of composite 


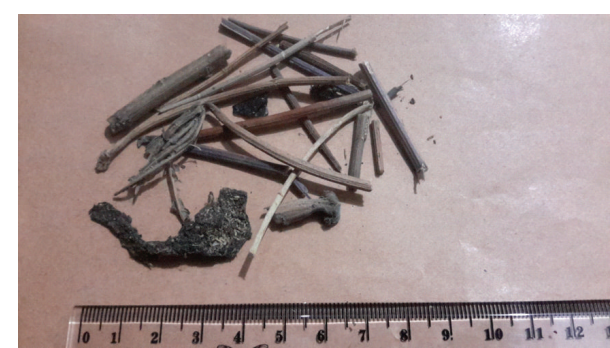

(a)

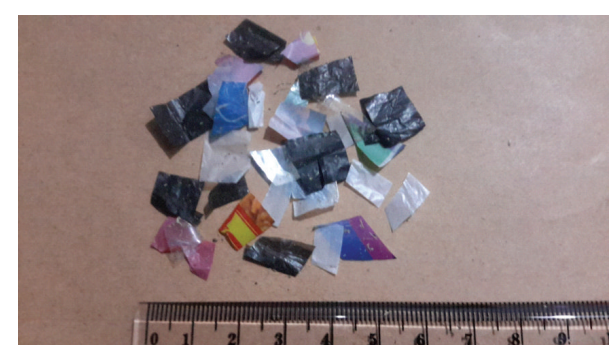

(b)

FIGURE 1: (a) Rough organic waste from a cutting machine and (b) pieces of plastic.

materials, such as wheat straw [7], bananas, bamboo, coir, coconut husk, sisal, rice husk [8], and sugar cane bagasse [9]. In this study, we introduce a method of using domestic wastes by turning them into composites that can be used as building materials. The created composites can be in the form of sheets or blocks that can be used to build houses for lowincome inhabitants. Many poor people in major cities live in houses made of tarpaulins or cardboard. They live with their children in unfit conditions and are vulnerable to disease. Building materials built from waste that could function like wood could provide cheap building materials to poor people. Furthermore, if the composites of the waste resemble the mechanical properties of wood, they can provide an alternative wood substitute material to reduce wood logging. We have previously reported the initial situation [10], and this paper will present a more comprehensive report of that study.

The composites we developed will be coated with fireretardant materials; therefore, the buildings made from this composite will also be resistant to fire (or take a longer time to burn). This coating could contribute to reducing the frequent fires that occur in densely populated settlements in major cities in Indonesia. Based on data from the Bandung Fire Department, 162 fire incidents occurred in Bandung in 2014, an increase from the 131 fire incidents in 2013. In 2015, there were 105 fire incidents in Bandung between January and August [11]. Fires occur more frequently during the dry season, from July to October [11], during which three to four times more fires occur than in other months. The main cause of fire incidents is electrical short circuits. Large cities in Indonesia frequently experience interruptions in electrical current, resulting in high numbers of fires in settlements.

The purpose of this research was to study the manufacture of a composite from domestic waste. This domestic waste is processed directly without chemical pretreatment to avoid the production of new waste. Pretreatment consists only of physical processes that do not add new waste. The composite waste is converted into a sheet that resembles a board. To increase its resistance to fire, a fire-retardant material, whose main component is phosphorus, is added to the composite.

The initial goal of this research was to determine components or synthesis parameters to obtain a composite with mechanical strength resembling wood used as building materials, such as albasia wood, with sufficient strength to build houses for people at low economic levels. The second goal was to coat the composite with a fire-retardant material and to analyze its fire-resistant properties.

As described previously, we want to use waste taken directly from landfills. However, because the waste disposed of each day varies in composition and the experiments were conducted over a long period, it was difficult to directly use waste from landfills. A more reliable step was to use samples of wastes whose composition resembled the average composition of wastes at several landfills in Bandung city. Therefore, we sampled the waste components at several landfills spread across the city, which were randomly selected, to determine the composition of the average domestic waste in Bandung. This composition was then used in the experiment.

To the best of our knowledge, no previous research focused on this topic has been reported by other researchers. The result of this research is expected to have a large impact on the community and government by providing decent and affordable settlement services for people at low economic levels. Simultaneously, the result of this study is expected to reduce logging and deforestation processes resulting from the search for building materials.

\section{Method}

In this study, we used polyvinyl acetate (PVAc) as a binder. The first step was to optimize the fraction of PVAc to produce composites with maximum compressive strength. The components of the composite were rough organic waste generated by a composting machine (GL), fine organic waste generated by a 15-hour milling process of rough organic waste (GS), and pieces of various types of paper, plastic, and cloth with a size of $75-150 \mathrm{~mm}^{2}$. The average size of the GL component was $2-7 \mathrm{~cm}$, while the scanning electron microscope (SEM) results showed that the average size of the GS component was $50 \mu \mathrm{m}$. Figure 1 shows rough waste that is the result of cutting machines and pieces of plastic.

Fabrication of the composite began by dissolving the PVAc (commercial trademark of FOX, PT Aica Indria, Indonesia) in $13 \mathrm{~mL}$ distilled water for 10 minutes until it became homogeneous. There was no pretreatment on the PVAc. Next, the PVAc solution was added to the waste components (i.e., GL: $6 \mathrm{~g}$, GS: $3 \mathrm{~g}$, paper: $1.5 \mathrm{~g}$, plastic: $1.5 \mathrm{~g}$, and cloth: $1 \mathrm{~g}$ ). The amount of PVAc varied from $1 \mathrm{~g}$ to $6 \mathrm{~g}$, while the total mass of the other components was maintained at 
$26 \mathrm{~g}$. The plastic component was acquired from a variety of packaging plastic waste (including pieces of plastic that were processed by a plastic slicer machine). The cloth component was a mixture of cotton and polyester, and the paper component was the waste of various types of paper, such as newsprint and magazines. The mixture was stirred for 15 minutes, followed by drying under a halogen lamp (lamp specifications: TN-0450 VATLUX 220/240 V 50/60 Hz, Max 500 watt; manufactured by Phillips; used in Bandung, West Java, Indonesia) at a distance of approximately $14 \mathrm{~cm}$ for 15 minutes to remove the water content. The dry mixture was then inserted into a cylindrical mold of stainless steel with an inner diameter of $25 \mathrm{~mm}$ and was pressed with a force of 2 tons at a temperature of $125^{\circ} \mathrm{C}$ for 30 minutes, followed by additional pressing for 30 minutes at room temperature. Samples were then left in the open air for at least 4 days. After this period, the mechanical strength was measured to determine the optimum amount of PVAc needed to produce the greatest compressive strength.

Using the optimum amount of PVAc, we varied the pressing temperature to obtain the optimum temperature for the formation of a composite with the greatest compressive strength. The amount of components used was GL: $6 \mathrm{~g}$, GS: $3 \mathrm{~g}$, paper: $1.5 \mathrm{~g}$, plastic: $1.5 \mathrm{~g}$, cloth: $1 \mathrm{~g}$, and water: $13 \mathrm{~mL}$, along with the optimum amount of PVAc. The hot-press temperature was varied between $125^{\circ} \mathrm{C}$ and $300^{\circ} \mathrm{C}$.

The next variation performed was the GS mass fraction of the total mass of GL + GS using the previously obtained PVAc quantity and the optimum temperature. We then varied the fraction of paper using the optimum amount of PVAc, the optimum temperature, and the optimum ratio of GS/(GL + GS). Next, we varied the amount of plastic using the optimum amount of PVAc, the optimum temperature, the optimum $\mathrm{GS} /(\mathrm{GL}+\mathrm{GS})$ ratio, and the optimum amount of paper. Finally, we adjusted the overall composition by varying the amount of cloth using the optimum amount of PVAc, the optimum temperature, the optimum GS/(GL + GS) ratio, and the optimum amounts of paper and plastic.

Next, we sampled the waste components in a number of landfills scattered through Bandung. Samples of approximately 1 bucket each were taken from each landfill with varied mass, depending on the type and condition of the waste (wet or dry). The net mass of the waste was between $2.5 \mathrm{~kg}$ and $6 \mathrm{~kg}$ per bucket. Generally, the waste was dry, except in several landfills that had been affected by rain. We measured the mass ratios of the five types of waste. We then separated the main components of the waste and calculated the weight to determine the mass fraction of each type of waste. Ten landfills were sampled. The average value of each component was used in the overall landfill composition.

We tried to improve the strength of the composite by adding dense silica filler to the mixer. We used commercial silica of nanometer size and silica derived from rice husks. We used the rice husks available commercially. Two types of silica rice husks were used; one was used directly and the other was used after 30 hours of milling to determine the effect of size on compressive strength. The milling tool was a cylinder with an inner diameter of $200 \mathrm{~mm}$ and rotational speed of $30 \mathrm{rpm}$. Twenty pieces of stainless-steel spherical bearings with a volume of $7.234,56 \mathrm{~mm}^{3}$ and a mass of $60 \mathrm{~g}$ were inserted into the milling tool for grinding.

To increase fire resistance, the composites were coated with a commercially available fire-retardant powder that is used in fire extinguishers. Two coating methods were tried. The first method was to mix the fire-retardant material with the waste components, which were mixed with the solution of PVAc and stirred until homogeneous. The second method was to mix the fire-retardant material with epoxy resin and hardener, stirred until even, used to coat the composite surface, and then air dried for 4-5 days. However, the epoxyhardener mixture was difficult to dry, even after 4-5 days. The function of the epoxy resin was to glue the fire-retardant powder to the surface of the composite board. When PVAc was used as the glue, the fire-retardant material agglomerated in the solution and made the coating process difficult. Therefore, the most efficient method, in terms of time and mechanics, was the mixing method, even though it decreased the compressive strength of the composite.

The fire-retardant test was conducted by placing a composite sample above a Bunsen burner at a distance of approximately $5 \mathrm{~cm}$ from the tip of the flame. This equipment was stored in a box made of iron plate, aluminum, and glass, and its volume was $54.450 \mathrm{~cm}^{3}$. The box had a gap for airflow. To measure the temperature of the fire, a thermocouple tool was used, and the end of the wire was inserted at the bottom of the composite. The thermocouple recorded the temperature and time during the burning process. Visual changes in the composite during the combustion process were recorded using a camera (Olympus $\mu$ 7030). Compressive strength measurements were performed using a device called the Sociedad Espanola Anonima Ibertest. SEM images and EDX elemental analysis were performed using a JSM-6510 LV (low vacuum).

\section{Results and Discussion}

3.1. Waste Composition in the City of Bandung. Figure 2 shows a map of Bandung taken from Google Maps, and the numbers indicate the locations where the waste was collected. The components recorded were only the dominant components; all of the nondominant components were grouped into the "others" category. The sampling process took place in the early rainy season; therefore, in some places the waste was dry while in others it was wet.

Table 1 shows the average composition of the waste in several landfills in Bandung. Measurement results appearing in Table 1 are the averaged measurements over seven samples on different days, and each sample was performed at three different positions in the stack of waste. These data were collected to obtain a more accurate representation of the waste composition. The composition of organic waste was almost the same for each landfill, approximately 50\% (average, 53.49\%) (Table 1). The composition of plastic waste was also relatively similar for all locations, approximately 20\% (average, $21.73 \%$ ). A clear correlation between the amounts of organic and plastic wastes was observed.

Bandung citizens put all of their groceries in plastic bags. The largest quantities of goods they buy are foods, which 
TABLE 1: Composition of the main components of waste at several landfills in Bandung.

\begin{tabular}{|c|c|c|c|c|c|c|}
\hline Number & Location & $\begin{array}{c}\text { Plastic } \\
\text { (mass\%) }\end{array}$ & $\begin{array}{c}\text { Paper } \\
\text { (mass\%) }\end{array}$ & $\begin{array}{c}\text { Textile } \\
\text { (mass\%) }\end{array}$ & $\begin{array}{c}\text { Organics } \\
\text { (mass\%) }\end{array}$ & $\begin{array}{c}\text { Others } \\
\text { (mass\%) }\end{array}$ \\
\hline 1 & Puter & 25.3 & 7.4 & 13.6 & 49.7 & 4.0 \\
\hline 2 & Ambon & 21.2 & 16.1 & 3.2 & 56.5 & 3.1 \\
\hline 3 & Patrakomala & 20.6 & 12.3 & 9.4 & 53.0 & 4.7 \\
\hline 4 & Kosambi & 24.7 & 11.5 & 10.7 & 48.1 & 5.1 \\
\hline 5 & Gudang Selatan & 23.5 & 16.0 & 4.1 & 52.9 & 3.5 \\
\hline 6 & Cibatu Antapani & 21.5 & 11.6 & 8.6 & 56.4 & 1.9 \\
\hline 7 & Cijambe & 20.8 & 9.8 & 10.6 & 55.6 & 3.2 \\
\hline 8 & Sederhana & 22.7 & 12.8 & 6.6 & 52.6 & 5.3 \\
\hline 9 & Ciroyom & 20.4 & 9.6 & 6.3 & 58.9 & 4.8 \\
\hline 10 & Cijawura & 16.6 & 12.8 & 17.5 & 51.2 & 1.9 \\
\hline \multicolumn{2}{|c|}{ Average } & 21.73 & 11.99 & 9.06 & 53.49 & 3.75 \\
\hline \multicolumn{2}{|c|}{$\sigma / x_{\text {ave }}$} & 0.109 & 0.215 & 0.455 & 0.059 & 0.315 \\
\hline
\end{tabular}

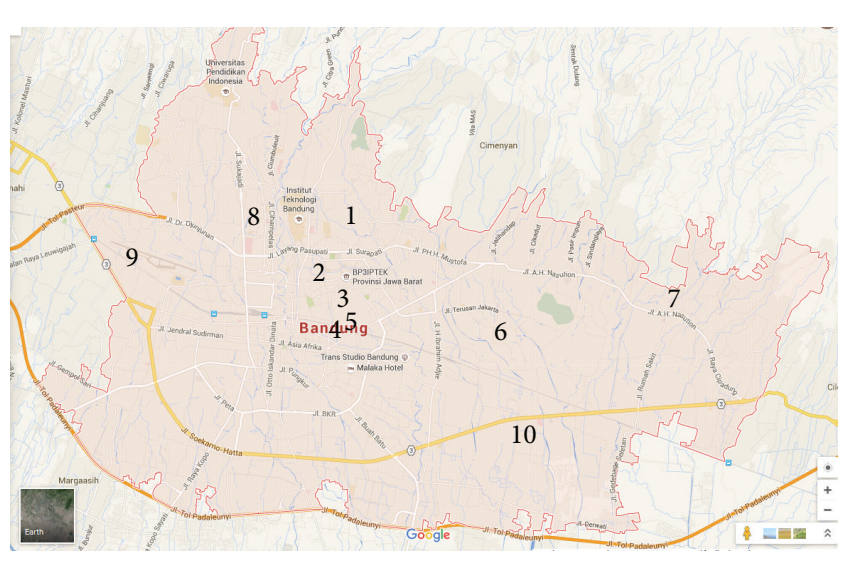

Figure 2: Map of Bandung from Google Maps. The numbers indicate the locations where the waste was collected: (1) Puter, (2) Ambon, (3) Patrakomala, (4) Kosambi, (5) Gudang Selatan, (6) Cibatu Antapani, (7) Cijambe, (8) Sederhana, (9) Ciroyom, and (10) Cijawura.

are generally in the form of organic matter. Leftover food comprises most organic waste.

We also determined the standard deviation for each landfill using the following equation [12]:

$$
\sigma=\sqrt{\frac{1}{n} \sum_{i=1}^{n}\left(x_{i}-x_{\mathrm{ave}}\right)^{2}}
$$

where $n$ is the number of samples (at the landfills), $x_{i}$ is the composition of the $i$ th landfill, and $x_{\text {ave }}$ is the average value of these components in all the landfills. The size of the waste content variation is the ratio between the deviation standard and the average value, $\sigma / x_{\text {ave }}$. Table 1 shows the ratios for all the waste components. The values of $\sigma / x_{\text {ave }}$ for organic waste and plastic were very small compared to other components, 0.109 and 0.059 , respectively. Thus, the fraction of plastic and organic waste deposited by Bandung residents was the same regardless of the geographic location.

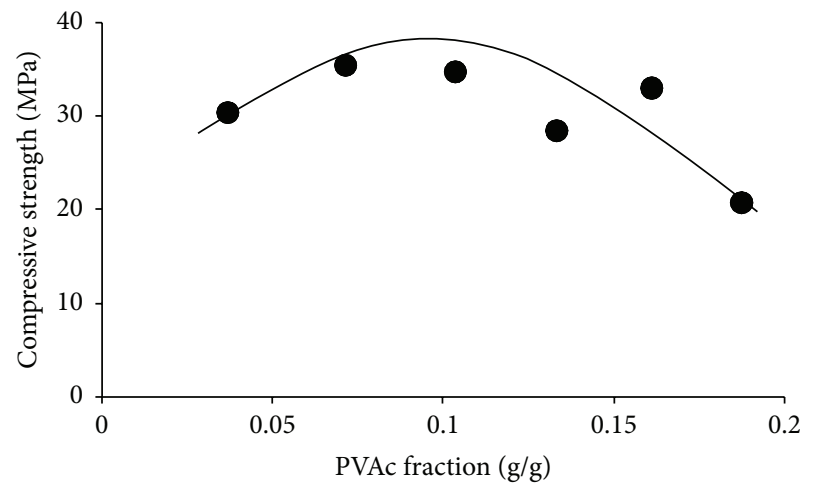

FIgURE 3: Effect of the PVAc fraction on the composite compressive strength. The synthesis parameters used were as follows: $6 \mathrm{~g} \mathrm{GL}, 3 \mathrm{~g}$ GS, $1.5 \mathrm{~g}$ paper, $1.5 \mathrm{~g}$ plastic, $1 \mathrm{~g}$ cloth, and $13 \mathrm{~mL}$ water.

Figure 3 shows the effect of variations in the mass fraction of PVAc on the compressive strength of a waste composite that only contained GL, GS, plastic, paper, cloth, and PVAc. The compressive strength increased with increasing PVAc fraction and then decreased after reaching a maximum at $35 \mathrm{MPa}$ when the PVAc fraction was approximately $0.1 \mathrm{~g} / \mathrm{g}$. The temperature of the hot press was $125^{\circ} \mathrm{C}$ for all sample processes.

The behavior shown in Figure 3 is typical of the composite. Too much or too little binder did not produce maximum strength. The maximum strength of the composite was reached at a certain amount of binder or filler, which was related to the contact between the binder and the filler. The maximum strength correlated with a maximum amount of contact, which occurred at specific fractions of filler and binder, respectively.

\subsection{The Effect of Hot-Press Temperature on the Compressive} Strength of the Composite. Using the PVAc fraction of $0.1 \mathrm{~g} / \mathrm{g}$, which provided the maximum compressive strength (Figure 3), we varied the temperature during the pressing process. 


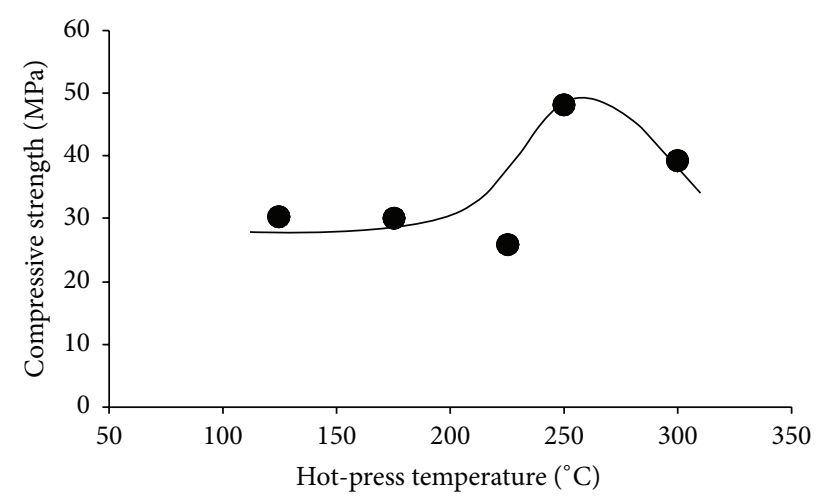

FIGURE 4: Effect of the hot-press temperature on the composite compressive strength. Synthesis parameters used were as follows: $6 \mathrm{~g}$ GL, $3 \mathrm{~g}$ GS, $1.5 \mathrm{~g}$ paper, $1.5 \mathrm{~g}$ plastic, $1 \mathrm{~g}$ cloth, $3 \mathrm{~g}$ PVAc, and $13 \mathrm{~mL}$ water.

We varied the temperatures between $125^{\circ} \mathrm{C}$ and $300^{\circ} \mathrm{C}$. The temperature was measured at the top of the hot-press clamp using an infrared laser thermometer at a distance of approximately $8.5 \mathrm{~cm}$. The recorded temperature was the average temperature because only slight variations occurred in the readings during the measurement process.

The effect of temperature on compressive strength is shown in Figure 4. The pressing temperature that gave the highest compressive strength was $250^{\circ} \mathrm{C}$. The compressive strength at that temperature was approximately $48 \mathrm{MPa}$, which was approximately $37 \%$ greater than the compressive strength at a pressing temperature of $125^{\circ} \mathrm{C}$.

Variations in the temperature below $225^{\circ} \mathrm{C}$ had almost no effect on the resulting compressive strength. At these temperatures, we assumed that the perfect pasting of the PVAc chains onto the filler had not yet occurred; therefore, the bond between the PVAc and the filler had not been well set. At $250^{\circ} \mathrm{C}$, the most optimal adhesion of PVAc on the filler surface occurred, and therefore the best bond was formed. Above $250^{\circ} \mathrm{C}$, PVAc tended to flow and accumulated at the bottom, and the adhesion of the PVAc-filler surface detached.

\subsection{Effects of the Small Organic Granular Mass Fraction on} Compressive Strength. Using both the mass fraction of PVAc and the temperature that provided the maximum compressive strength $\left(0.1 \mathrm{~g} / \mathrm{g}\right.$ and $250^{\circ} \mathrm{C}$, resp.), we varied the mass fraction of the small-sized waste to the large-sized waste. The total mass of both types of waste was retained at $9 \mathrm{~g}$ (Figure 5). The highest compressive strength was achieved using a mass fraction of GS/(GL + GS) approaching $0.45 \mathrm{~g} / \mathrm{g}$, which resulted in a value of compressive strength of approximately $48 \mathrm{MPa}$. This strength was due to the small waste filling the space between the grains of the large waste. The maximum strength of the composite was achieved when almost all the space between the large-sized wastes was filled by the smallsized waste.

The volume of space between the large-sized wastes can be estimated as follows. Assuming that the granular waste is relatively spherical, the space volume between the balls is determined by the packing fraction of the balls. The packing

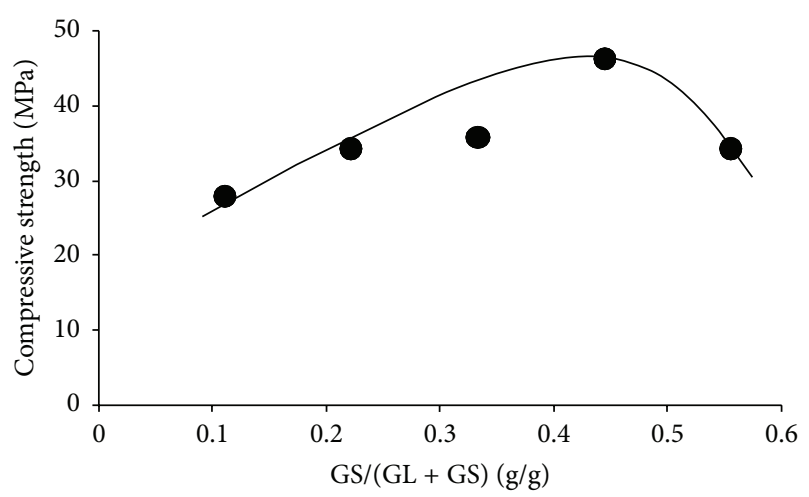

FIGURE 5: Effect of the mass fraction GS/(GL + GS) on the composite compressive strength. The total mass of $(\mathrm{GL}+\mathrm{GS})$ was retained at $9 \mathrm{~g}$. The other parameters used were as follows: $1.5 \mathrm{~g}$ paper, $1.5 \mathrm{~g}$ plastic, $1 \mathrm{~g}$ cloth, $3 \mathrm{~g}$ PVAc, $13 \mathrm{~mL}$ water, and a hot-press temperature of $250^{\circ} \mathrm{C}$.

fraction depends on how the balls are formed and whether they approach the form of a simple cube, a body-centered cube, a face-centered cube, or hexagonal closed packing. The most regular forms are the face-centered cube and hexagonal closed packing. The simplest form is the body-centered cube in which each cell only contains one ball. The packing fraction in the form of a simple cubic is $\left(\pi a^{3} / 6\right) / a^{3}=\pi / 6=0.52$ [13], where $a$ is the diameter of the ball. Therefore, the fraction of free space in the simple cubic form is $1-0.52=0.48$.

If the granular waste is stirred, there is only a small likelihood of forming a regular structure. The structure of these granular materials is less likely to be regular, and if it is regular, it likely approaches the simple cubic form. Therefore, the volume of empty space generated will be approximately $48 \%$. This empty space is then filled by the small grains. Therefore, the fraction of big waste and small waste is approximately the same, and if each is approximately $50 \%$, the result is maximal filling (Figure 5).

3.4. The Effect of the Mass Fractions of Paper and Plastic on Compressive Strength. We also examined the effect of the mass fraction of paper on compressive strength. The previous optimum parameters were used: $0.1 \mathrm{~g} / \mathrm{g}$ PVAc, a pressing temperature of $250^{\circ} \mathrm{C}$, and a proportion of small organic waste fraction to the total mass of organic waste of $45 \%$. Figure 6 indicates that the mass fraction of paper that gives the highest compressive strength was $0.08 \mathrm{~g} / \mathrm{g}$ with a compressive strength value slightly greater than $49 \mathrm{MPa}$.

Finally, we varied the mass of plastic using the optimum parameters for the PVAc fraction, pressing temperature, small waste mass fraction, and paper mass fraction (Figure 7). We concluded that the mass fraction of plastics that provided the highest compressive strength was approximately $0.03 \mathrm{~g} / \mathrm{g}$. At this fractional mass, the compressive strength was approximately $56 \mathrm{MPa}$.

Based on these results, we determined the synthetic parameters that provided the maximum strength of the composite material (Table 2). The highest compressive strength achieved was approximately $56 \mathrm{MPa}$. The mass fraction values 
TABLE 2: The optimum parameters that produce the highest compressive strength. The hot-press temperature used was $250^{\circ} \mathrm{C}$. The figures inside brackets are the mass fractions, which were calculated from the dry composite (after the water evaporated).

\begin{tabular}{|c|c|c|c|c|c|c|c|}
\hline & PVAc & GL & GS & Paper & Plastic & Cloth & Water \\
\hline Mass (g) & 3 & 5 & 4 & 2.5 & 1 & 1 & 13 \\
\hline Mass fraction (\% g/g) & $10.2(18.2)$ & $16.9(30.3)$ & $13.6(24.2)$ & $8.5(15.2)$ & $3.4(6.05)$ & $3.4(6.05)$ & 44.0 \\
\hline
\end{tabular}

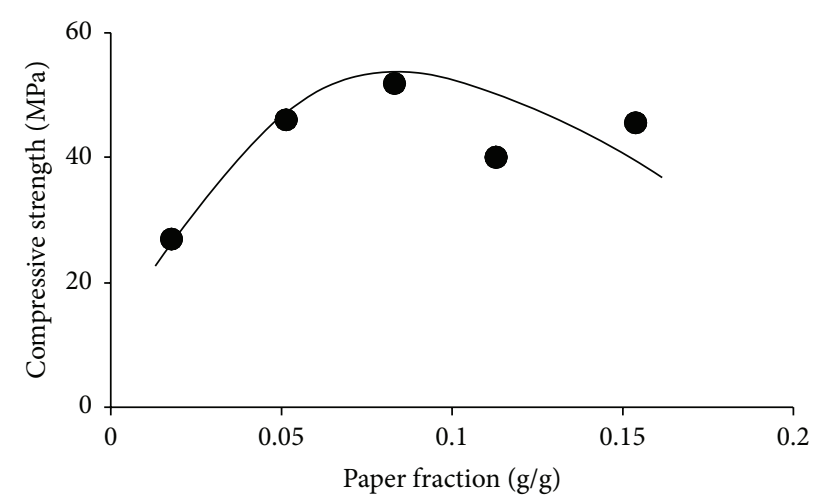

FIGURE 6: Effect of the paper mass fraction on the composite compressive strength. The other parameters used were as follows: $3 \mathrm{~g}$ of PVAc, $4 \mathrm{~g}$ of GS, $5 \mathrm{~g}$ of GL, $1.5 \mathrm{~g}$ of plastic, $1 \mathrm{~g}$ of cloth, $13 \mathrm{~mL}$ of water, and a hot-press temperature of $250^{\circ} \mathrm{C}$.

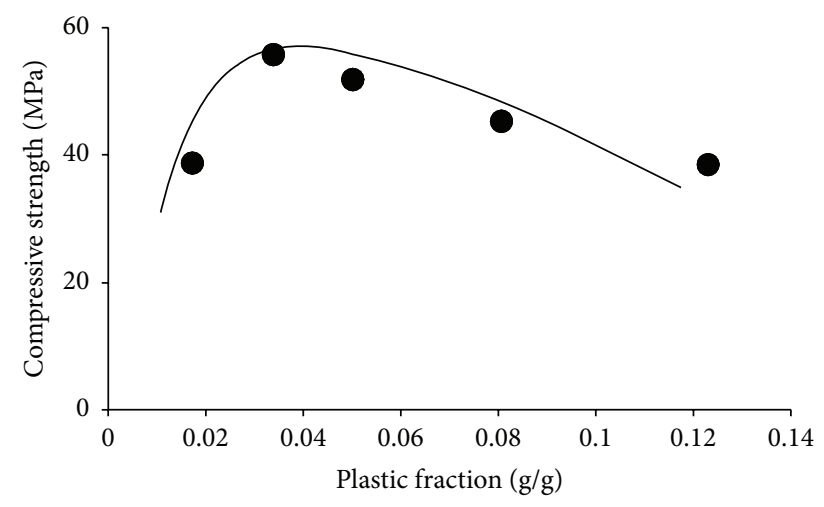

FIGURE 7: Effect of the plastic mass fraction on the composite compressive strength. The other parameters used were as follows: $3 \mathrm{~g}$ PVAc, $4 \mathrm{~g}$ GS, $5 \mathrm{~g}$ GL, $1.5 \mathrm{~g}$ paper, $1 \mathrm{~g}$ cloth, $13 \mathrm{~mL}$ water, and a hot-press temperature of $250^{\circ} \mathrm{C}$.

shown in brackets in Table 2 were calculated excluding the contribution of water, that is, the mass fraction of the dry composite after the water had evaporated.

Notably, in the composite manufacturing process, no chemical pretreatment was included; therefore, our processing of the waste did not generate new waste. Chemical pretreatment could increase the strength of the composite because the surface modification of components would occur before the mixing process. These modifications could result in a stronger bond between the composite components. This step was not taken because we did not intend to pursue the highest possible mechanical strength. Our goal was to make a composite with sufficient mechanical strength for the manufacture of a new building without generating new waste.

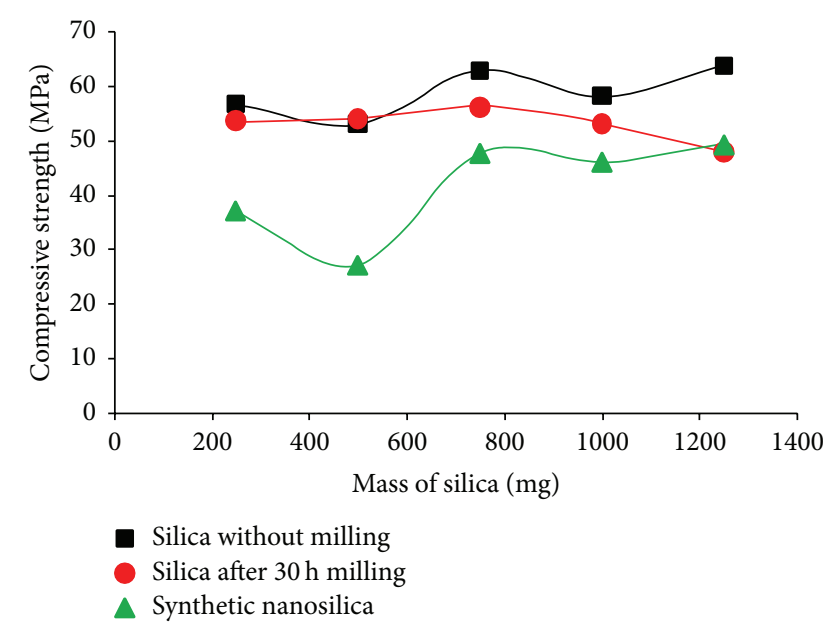

FIGURE 8: Effect of the silica mass on the compressive strength: (a) nanosilica, (b) rice husk, and (c) rice husk after 30 hours of milling.

Interestingly, the waste composition that yielded the maximum compressive strength was similar to the average existing waste composition in Bandung. If we assume that the PVAc and plastic are categorized as plastic in Table 1, Table 2 gives a value of $24.25 \%$ for plastic, which is similar to the value in Table 1 of $21.73 \%$. GL and GS in Table 2 form organic components with a total value of $54.5 \%$, which approaches the average value of $53.47 \%$ in Table 1 . In Table 2, the paper mass fraction is $15.2 \%$, fairly close to the waste paper fraction in Bandung, which is $11.98 \%$. The cloth mass fraction in Table 2 is $6.05 \%$, which is not far from the cloth waste fraction in Bandung, which is $9.08 \%$. These results are very interesting; the Bandung municipal waste can be used directly to make the composite with maximum strength.

3.5. The Effect of Adding Silica to the Compressive Strength. The effect of adding silica to the compressive strength is shown in Figure 8. Other parameters used to make these composites are the same as those in Table 2. Figure 9 shows SEM photographs of a rice husk that has not undergone the milling process and a rice husk that has undergone 30 hours of milling for the manufacture of the composites. The size of a rice husk is approximately $30 \mu \mathrm{m}$, and the size of a husk milled for 30 hours is $1-10 \mu \mathrm{m}$. The morphology of the nanosilica has been reported previously [14] and had an average size of approximately $75 \mathrm{~nm}$. We varied the silica mass from $250 \mathrm{mg}$ to $1,250 \mathrm{mg}$; the mass fraction was varied between $0.015 \mathrm{~g} / \mathrm{g}$ and $0.07 \mathrm{~g} / \mathrm{g}$.

Figure 8 shows that the silica in the rice husk without milling yielded the highest compressive strength of approximately $63 \mathrm{MPa}$ using $750 \mathrm{mg}$ of rice husk (a mass fraction 


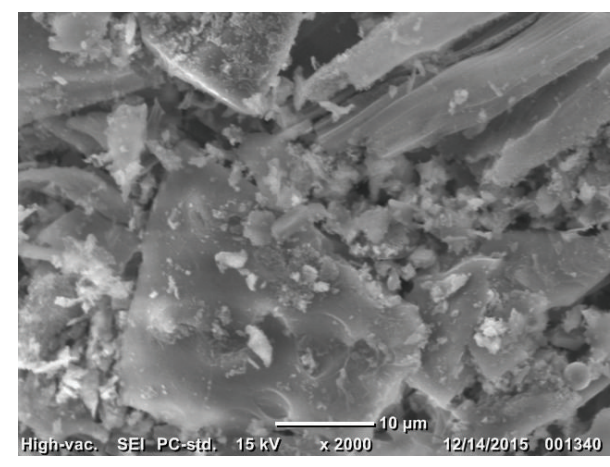

(a)

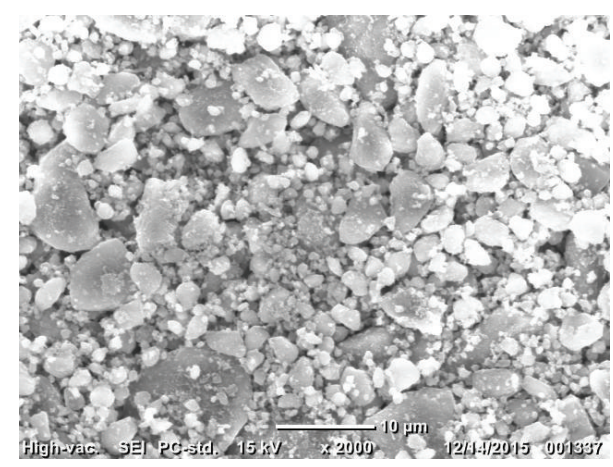

(b)

FIGURE 9: SEM images of (a) rice husk without undergoing the milling process and (b) rice husk after undergoing a 30-hour milling process.

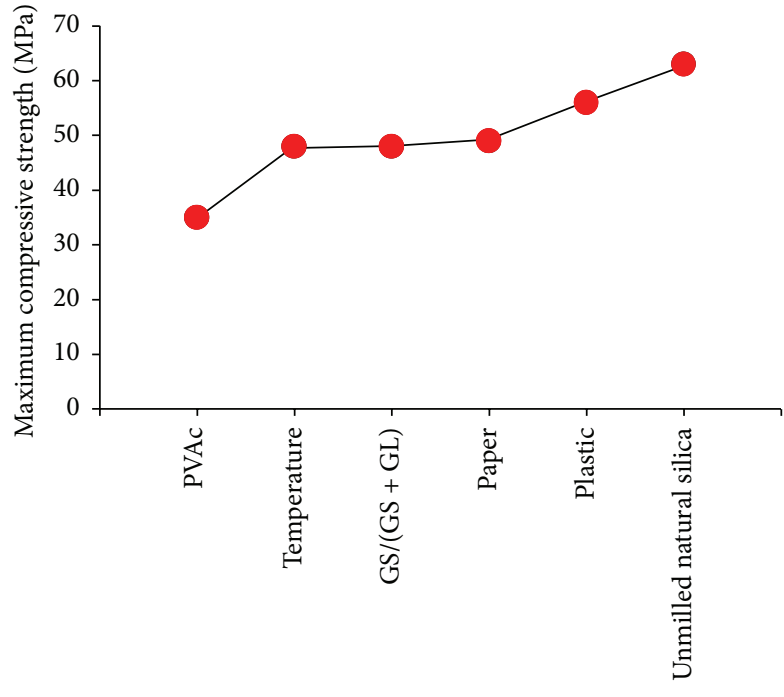

Parameter variation

FIGURE 10: The maximum compressive strength obtained from the sequential variation of parameters. The direction of the variation in parameters is from left to right. Unmilled natural silica is rice husk that has not undergone the milling process.

of $0.043 \mathrm{~g} / \mathrm{g}$ ). Nanosilica produced the smallest force. The compressive strength increased almost linearly with the increasing of fraction of natural silica but decreased with the addition of natural silica that was milled for 30 hours. The addition of nanosilica initially increased the compressive strength, and it became constant at $50 \mathrm{MPa}$ when the content of nanosilica was already quite high.

Figure 10 provides a summary of the synthesis parameter variation and the maximum compressive strength values obtained. The highest compressive strength obtained was $63 \mathrm{MPa}$. This value is equivalent to the strength of the composite we reported earlier for composites made from leaf and paper waste whose composite strength reached 55.7 $\mathrm{MPa}$ [15].

Figure 8 shows that the silica in the rice husk without milling yielded the highest compressive strength of approximately $63 \mathrm{MPa}$ using $750 \mathrm{mg}$ of rice husk (a mass fraction of $0.043 \mathrm{~g} / \mathrm{g}$ ). Nanosilica produced the smallest force.

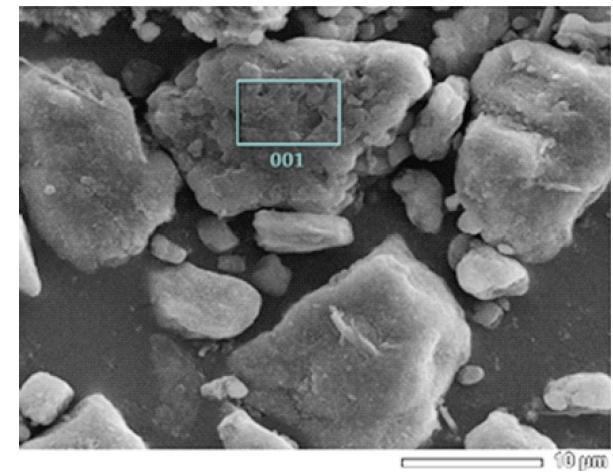

FIGURE 11: An SEM image of a commercial fire-retardant material.

The compressive strength increased almost linearly with the increasing of fraction of natural silica but decreased with the addition of natural silica that was milled for 30 hours. The addition of nanosilica initially increased the compressive strength, and it became constant at $50 \mathrm{MPa}$ when the content of nanosilica was already quite high.

Figure 10 provides a summary of the synthesis parameter variation and the maximum compressive strength values obtained. The highest compressive strength obtained was $63 \mathrm{MPa}$. This value is equivalent to the strength of the composite we reported earlier for composites made from leaf and paper waste whose composite strength reached 55.7 MPa [15].

3.6. The Effect of the Addition of Fire-Retardant Material. The fire-retardant material used was composed of particles with sizes on the order of micrometers, and most of them were larger than $10 \mu \mathrm{m}$ (Figure 11). An EDX analysis revealed that the main component of the material was $\mathrm{P}_{2} \mathrm{O}_{5}$ with a mass fraction of $92.58 \%$. Other identified components were $\mathrm{Na}_{2} \mathrm{O}$ (1.07\% mass), $\mathrm{MgO}$ (3.34\% mass), $\mathrm{Al}_{2} \mathrm{O}_{3}$ (1.26\% mass), $\mathrm{SiO}_{2}$ (1.01\% mass), and $\mathrm{FeO}$ (0.73\% mass).

First, we compared the heating rate of a composite that was not coated with fire-retardant material to a coated one. They were burned in the same fire, and the temperatures of the composites were measured as a function of time. Figure 12 shows the temperature change of both composites with 


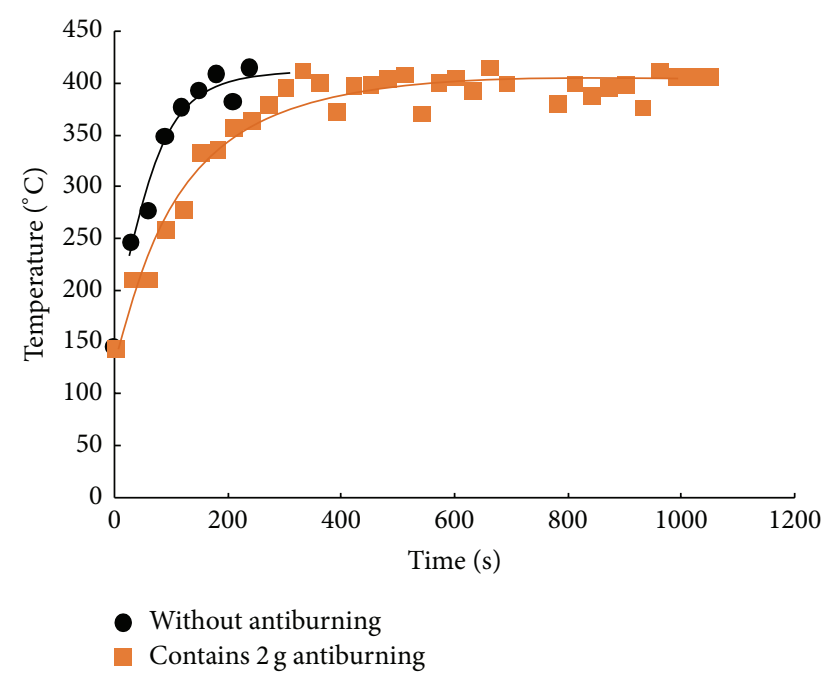

FIgURE 12: Changes in the temperature of a coated composite with fire-retardant material and an uncoated one during the burning process.

respect to time. The amount of coating material used, which was applied to the composite surface area of $2,943.75 \mathrm{~cm}^{2}$, was $2 \mathrm{~g}$. Clearly, the uncoated composite underwent a more rapid temperature increase than the coated one. The uncoated composite reached a temperature of $400^{\circ} \mathrm{C}$ in slightly less than 200 seconds, while the composite coated with fire-retardant material reached temperatures of $400^{\circ} \mathrm{C}$ after 300 seconds.

Furthermore, visual observations of the effect of the additional fire-retardant were conducted by examining the color of both the coated and uncoated composites during the same burning process. To obtain the same scorched color on both composites, the uncoated composite required only 4.26 minutes, while the coated one required 19 minutes. These results indicate that a coating with fire-retardant material could actually delay the temperature increase in the composite; therefore, it could delay the occurrence of large fires. This delay in the temperature increase was due to the phosphorus pentoxide, which protected the sample from interactions with oxygen, thereby slowing the combustion process $[14,16]$.

Combustion occurs as a result of a pyrolysis process that decomposes dense composite samples with the help of oxygen from the surrounding air and high temperatures, which cause the release of heat, gas, and light continuously as a chain of chemical reactions [17]. The burning process was slowed by inhibiting the interaction and breaking the chain reaction using a phosphorus-based, solid-carbon type fire-retardant [17]. The condensation phase of the decomposition reaction yielded phosphoric acid $\left(\mathrm{H}_{3} \mathrm{PO}_{4}\right)$, which became a barrier to the evaporation process of the polymer hydrocarbon composite $[14,18] . \mathrm{H}_{3} \mathrm{PO}_{4}$ was lifted by the gas that was formed in the heating process; therefore, it underwent carbonization (the process of converting organic material into charcoal at low temperature; it was colored black and contained volatile matter) by forming a layer of charcoal that was accompanied by the release of water vapor. $\mathrm{P}_{2} \mathrm{O}_{5}$, an anhydrous form of $\mathrm{H}_{3} \mathrm{PO}_{4}$, formed a layer of charcoal (volatile) as a thermal

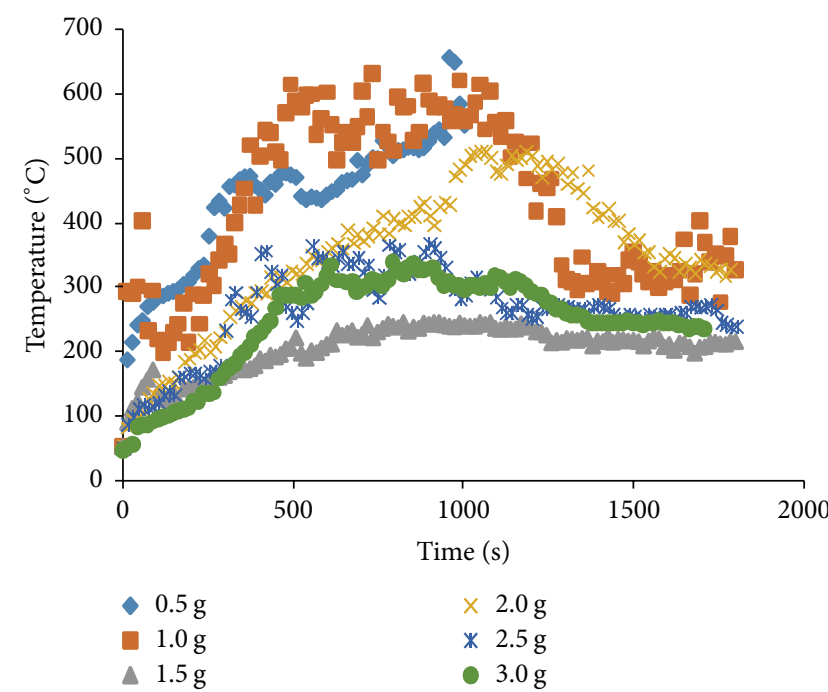

FIGURE 13: Change in the composite temperature with time using different masses of fire-retardant material.

protector and inhibited the oxidation process; therefore, the heat transfer and the introduction of oxygen into the combustion process were blocked [14, 16-20].

We also optimized the amount of fire-retardant material that produced the best delay time in the combustion process. We coated a composite with $38 \mathrm{~cm}^{2}$ of surface size with fireretardant coating. The amount of fire-retardant coating on the composite varied from $0.5 \mathrm{~g}$ to $3 \mathrm{~g}$. The results of the measurements of temperature changes during combustion are shown in Figure 13. It appears that the slowest rate of combustion occurred when $1.5 \mathrm{~g}$ of the fire-retardant material was used. This result was unexpected because we initially assumed that the more fire-retardant material we used, the better the rate of combustion. In fact, fire resistance reached an optimum level at $1.5 \mathrm{~g}$. We are notable to explain this result at this time.

In addition, we compared the rate of combustion of the composite to those of natural wood (albasia) and commercial particle board (Figure 14). The composites we made had better fire-retardant effects than either albasia wood or particle board. Clearly, the composites we synthesized were more resistant to combustion. The composite we made contained a number of components, including PVAc (which is difficult to burn) [21], whereas natural wood contains only one component, which is flammable. Particle board generally contains only two components, wood particles and binder; therefore, it is more difficult to ignite than wood, but it is more flammable than the composites we made.

\section{Conclusion}

We succeeded in making composites from domestic wastes to produce building materials with better mechanical strength. We achieved the highest mechanical strength of $63 \mathrm{MPa}$ using the following synthesis parameters: a hot-press temperature of $250^{\circ} \mathrm{C}, 10.2 \mathrm{wt} \%$ PVAc, $16.9 \mathrm{wt} \%$ rough organic waste generated from a composting machine, $13.6 \mathrm{wt} \%$ fine organic 


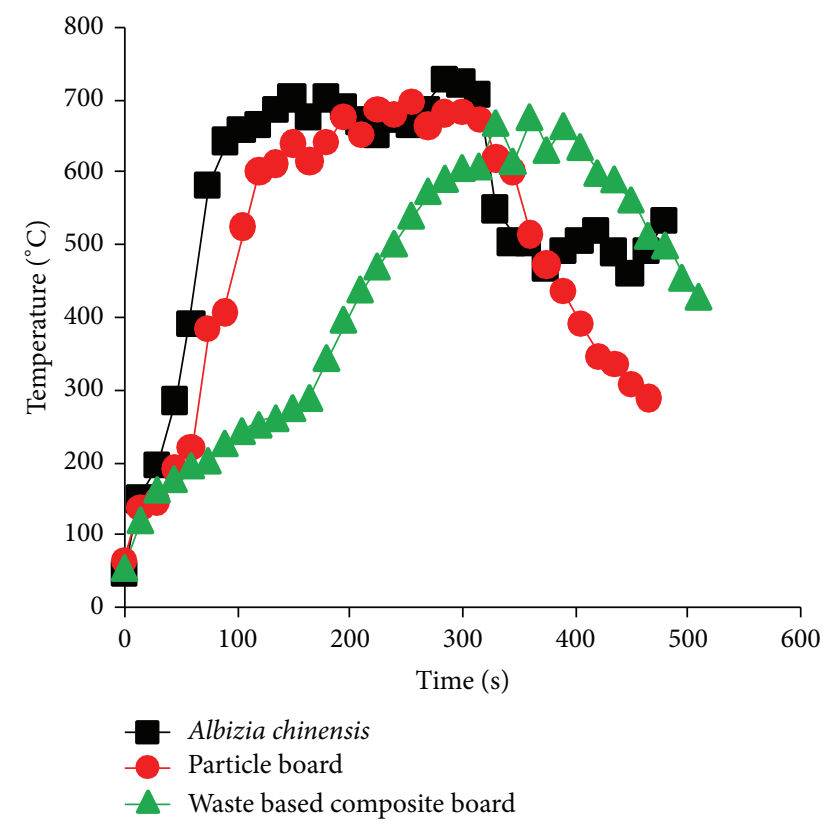

Figure 14: Changes in the rate of temperature increase in albasia wood, particle board, and the composite as a function of time. All samples were burned in the same way.

waste generated from a 15-hour milling process of rough organic waste, $8.5 \mathrm{wt} \%$ paper, $3.4 \mathrm{wt} \%$ plastic, $3.4 \mathrm{wt} \%$ cloth, and $44 \mathrm{wt} \%$ water. Compared with natural wood (albasia) and commercial particle board, the fire-retardant powdercoated composite was able to retard fire approximately four times longer. This composite could become a useful material for the construction of residential homes for poor people in Bandung, where fires occur regularly.

\section{Competing Interests}

The authors declare that they have no competing interests.

\section{Acknowledgments}

This work was supported by a Research Grant (no. 310y/ I1.C01/PL/2015) from the Ministry of Research and Higher Education, Republic of Indonesia, 2015-2017.

\section{References}

[1] West Java Province, West Java in Figure, 2011, http://www.pusdalisbang.jabarprov.go.id/pusdalisbang/berkas/jabardalamangka/ 524277_penduduk.pdf.

[2] T. M. Majka and K. Pielichowski, "Application of waste plastics for efficient flood protection systems," in Proceedings of the 1st World Sustainable Forum, November 2011.

[3] PlasticsEurope, The Compelling Facts about Plastics 2007: An Analysis of Plastics Production, Demand and Recovery for 2007 in Europe, PlasticsEurope, Brussels, Belgium, pp. 4-25, 2008.
[4] B.-I. Bae, H.-K. Choi, and C.-S. Choi, "Flexural strength evaluation of reinforced concrete members with ultra high performance concrete," Advances in Materials Science and Engineering, vol. 2016, Article ID 2815247, 10 pages, 2016.

[5] L. Luo, Y. Zhang, S. Bao, and T. Chen, "Utilization of iron ore tailings as raw material for portland cement clinker production," Advances in Materials Science and Engineering, vol. 2016, Article ID 1596047, 6 pages, 2016.

[6] C.-L. Hwang and T.-P. Huynh, "Evaluation of the performance and microstructure of ecofriendly construction bricks made with fly ash and residual rice husk ash," Advances in Materials Science and Engineering, vol. 2015, Article ID 891412, 11 pages, 2015.

[7] D. Wang and X. S. Sun, "Low density particleboard from wheat straw and corn pith," Industrial Crops and Products, vol. 15, no. 1, pp. 43-50, 2002.

[8] W. A. W. A. Rahman, L. T. Sin, A. R. Rahmat, N. M. Isa, M. S. N. Salleh, and M. Mokhtar, "Comparison of rice husk-filled polyethylene composite and natural wood under weathering effects," Journal of Composite Materials, vol. 45, no. 13, pp. 14031410, 2011.

[9] A. Getu and O. Sahu, "Green composite material from agricultural waste," International Journal of Agricultural Research and Review, vol. 2, no. 5, pp. 56-62, 2014.

[10] N. Surtiyeni, E. Yuliza, N. Kurniasih, Khairurrijal,, and M. Abdullah, "Effect of composition variation on the mechanical strength of domestic waste-based composites," Advanced Materials Research, vol. 1112, pp. 389-392, 2015.

[11] Department of Prevention and Mitigation Bandung, List of Fire Reports in 2015, 2015, http://ppid.bandung.go.id/informasi/laporan-kebakaran-bulanan-tahun-2015/.

[12] D. Moore and G. McCabe, Introduction to the Practice of Statistics, W.H. Freeman, New York, NY, USA, 3th edition, 1998.

[13] Mikrajuddin, F. G. Shi, and K. Okuyama, "Electrical conduction in insulator particle-solid-state ionic and conducting particleinsulator matrix composites. A unified theory," Journal of the Electrochemical Society, vol. 147, no. 8, pp. 3157-3165, 2000.

[14] G. F. Levchik, S. V. Levchik, P. D. Sachok, A. F. Selevich, A. S. Lyakhov, and A. I. Lesnikovich, "Thermal behaviour of ammonium polyphosphate-inorganic compound mixtures. Part 2. Manganese dioxide," Thermochimica Acta, vol. 257, pp. 117-125, 1995.

[15] Masturi, M. Abdullah, and Khairurrijal, "High compressive strength of home waste and polyvinyl acetate composites containing silica nanoparticle filler," Journal of Material Cycles and Waste Management, vol. 13, no. 3, pp. 225-231, 2011.

[16] L. A. Lowden and T. R. Hull, "Flammability behaviour of wood and a review of the methods for its reduction," Fire Science Reviews, vol. 2, no. 1, article 4, 2013.

[17] A. R. Horrocks and D. Price, Fire Retardant Materials, Woodhead Publishing Limited, Cambridge, UK, 2001.

[18] B. Scharte, "Phosphorus-based flame retardancy mechanismsold hat or a starting point for future development?" Materials, vol. 3, no. 10, pp. 4710-4745, 2010.

[19] M. Jimenez, S. Duquesne, and S. Bourbigot, "Intumescent fire protective coating: toward a better understanding of their mechanism of action," Thermochimica Acta, vol. 449, no. 1-2, pp. 16-26, 2006.

[20] J.-W. Gu, G.-C. Zhang, S.-L. Dong, Q.-Y. Zhang, and J. Kong, "Study on preparation and fire-retardant mechanism analysis 
of intumescent flame-retardant coatings," Surface and Coatings Technology, vol. 201, no. 18, pp. 7835-7841, 2007.

[21] Ş. Kurt and B. Uysal, "Combustion properties of oak (Quercus robur L.) laminated veneer lumbers bonded with PVAc, PF adhesives and impregnated with some fire-retardants," Composite Interfaces, vol. 16, no. 2-3, pp. 175-190, 2009. 

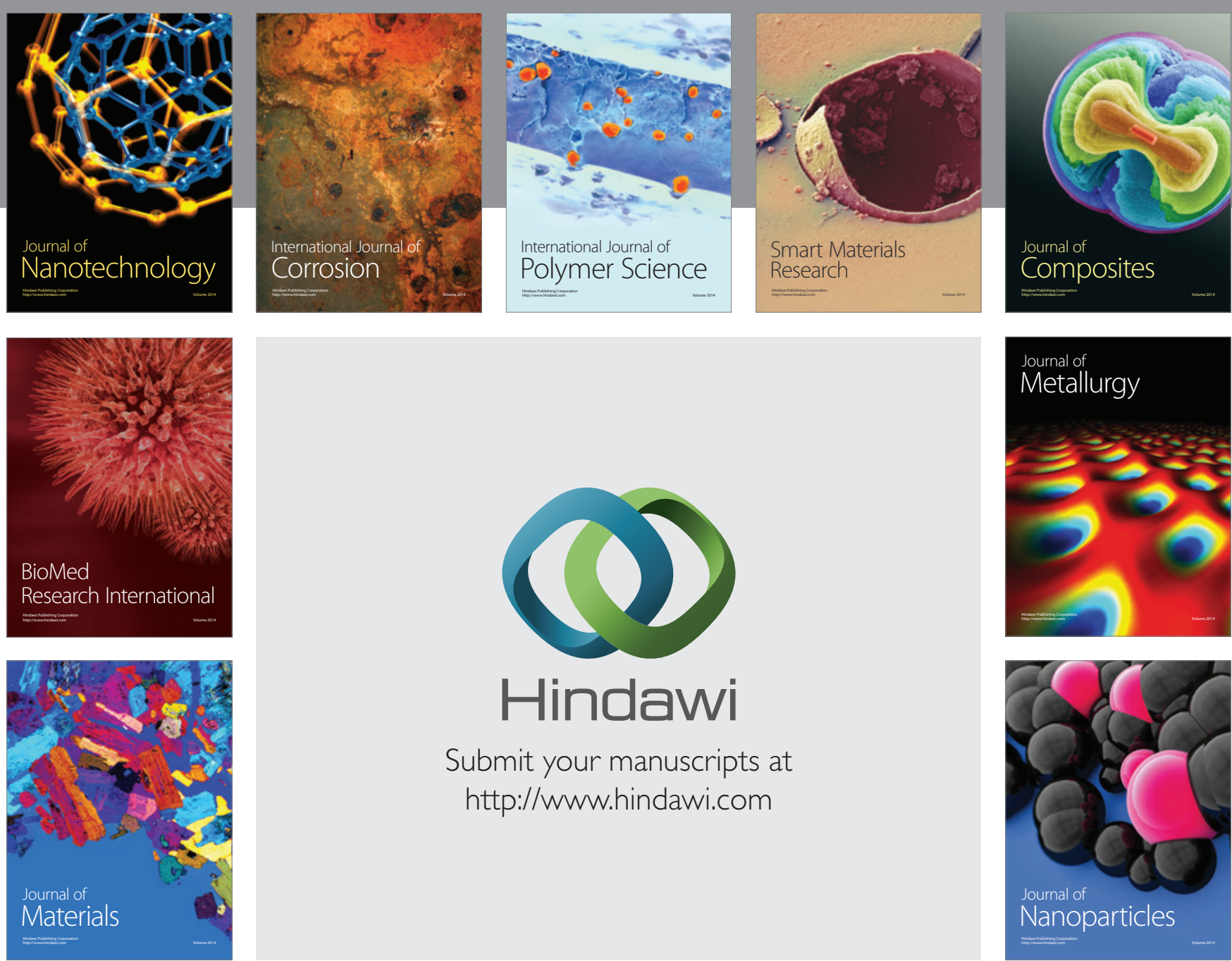

\section{Hindawi}

Submit your manuscripts at

http://www.hindawi.com

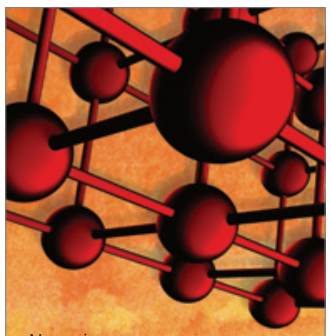

Materials Science and Engineering
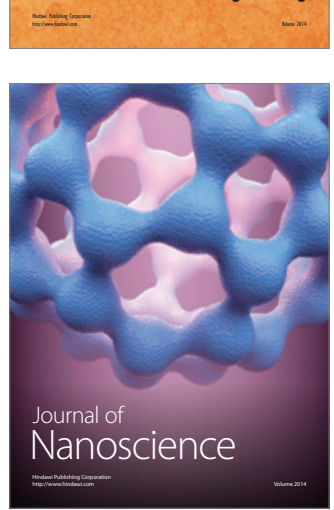
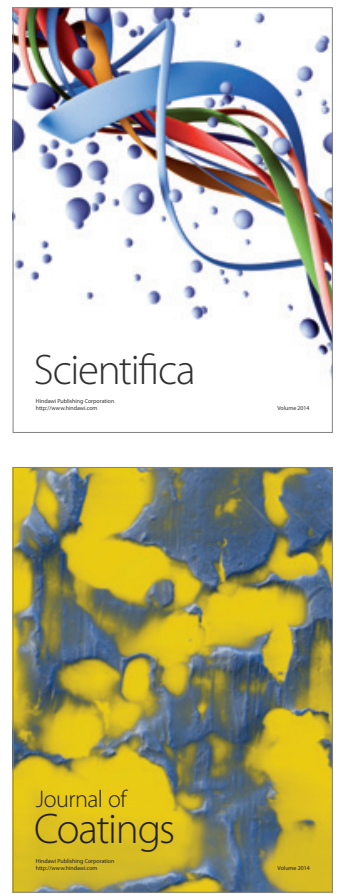
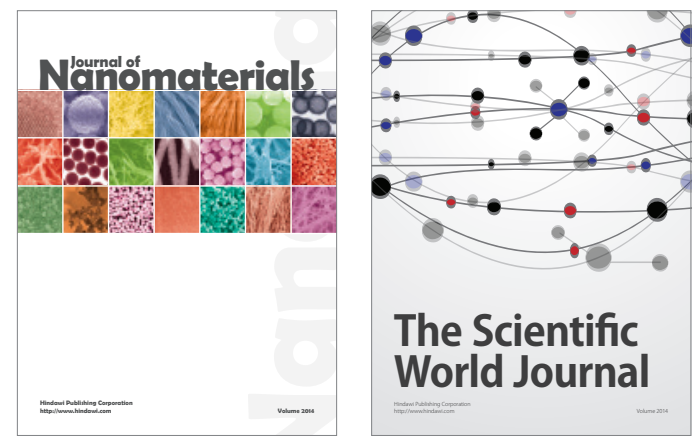

The Scientific World Journal
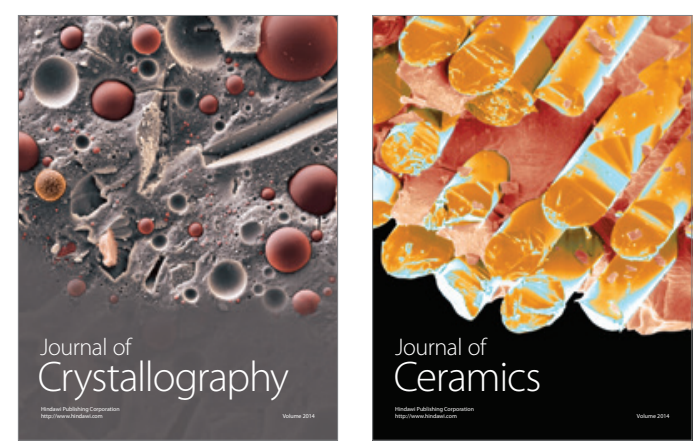
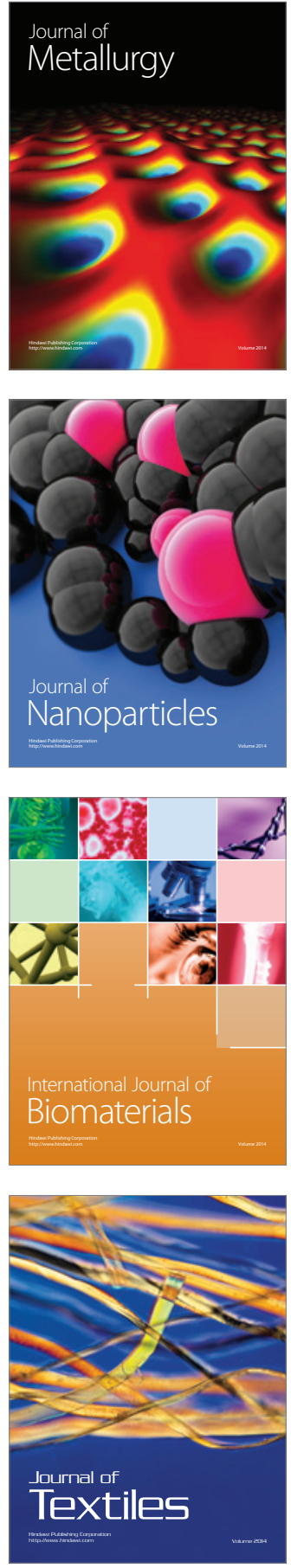